\title{
Influencing Factors of College Students' Willingness to Use Mobile Online Education Platforms
}

\author{
https://doi.org/10.3991/ijet.v16i22.26907 \\ Qian Feng ${ }^{1}$, Beikun Feng ${ }^{2(\mathbb{})}$ \\ ${ }^{1}$ Hubei Engineering University, Xiaogan, China \\ ${ }^{2}$ Hubei University of Technology, Wuhan, China \\ bdwg_whe163.com
}

\begin{abstract}
With the continuous progress of artificial intelligence technology, mobile online education is developing rapidly. Compared with traditional classrooms, the mobile online education mode can realize sharing of high-quality education resources efficiently and at a low cost, thus the education informatization policy can be implemented. However, the college students' willingness to use mobile online education platforms is complicated due to the lack of a market access threshold and relatively single course resources. Based on the theory of perceived value, the hypothesis of the influencing factors of the college students' willingness to use mobile online education platforms was proposed, and the hypothesis with a questionnaire survey method and structural equation model was verified. Results show that the questionnaire designed in this study has good reliability and validity. The exploratory learning and good public praise of the network positively affects the college students' perceived ease of use and perceived usefulness of mobile online education platforms. The perceived usefulness has a significant direct and positive effect on their willingness to use online education platforms. The conclusions have a certain reference value for improving the quality and service of online education platforms and enriching the connotation and usage of mobile online education.
\end{abstract}

Keywords - college students, mobile online, education platform, willingness to use, influencing factors

\section{Introduction}

Mobile online education refers to a teaching method that uses the Internet as a medium, wherein teachers and students conduct teaching activities through the network, and then breaks the limitations of time, space, manpower, and material resources, maximizing the resource utilization and resource sharing, which has obvious advantages in terms of learning autonomy, individualized teaching, and automatic management. With the continuous development of big data and cloud computing technology in China, mobile online education platforms have been integrated into people's lives and work. In recent years, with the increasing maturity of network technology and a large amount of capital entering the field of online education, online education in China has entered a 
stage of stable development. The "Government Work Report" in 2019 proposed the concept of "Internet + Education", in which the mobile online education platform can collect rich educational resources on the platform, the rich resources and modern expressions can make college students accept such personalized learning methods more. The mobile online education platform can conduct big data calculations based on the learning process and learning experiences of users, then introduce appropriate learning resources to users. The users can set their learning preferences, wherein mobile online platforms may provide a friendly way of resource presentation, which deepens good interaction between users and platform resources, thus providing the user with a friendly experience. The course content and organization form of mobile online platforms constantly presents new changes. The intelligent operation, interactive communication, and mobile use have gradually become the mainstream learning form of college students, the resource presentation and teaching mode are more intuitive, clear, and humanized.

As the mobile online education platforms gradually expand their application in the field of education, their platform resources are abundant and intelligent, which can fulfill the learning needs of all learning groups at different ages and shorten the time and space differences in education. With the maturity of the Internet, $5 \mathrm{G}$ technology, cloud technology, and VR/AR technology, college students are suitable for mobile online education. Artificial intelligence and mobile internet technology make mobile online education interactive and interesting, which can fulfill the personalized knowledge acquisition and skill training needs of college students outside the traditional classroom.

However, some mobile online education platforms lack resources and resource sharing. Under the influx of a large number of funds, numerous mobile online learning platforms pay more attention to hardware construction, which lacks systematic construction in terms of the resource content, user needs, and learning evaluation of mobile online platforms, as the evaluation on academic conditions of college students does not fulfill the needs of teachers and students, leading to a lack of learning enthusiasm from college students. Problems such as accelerated market competition, product homogeneity, and weak willingness of users have also gradually emerged in the mobile online education market. Therefore, analyzing the willingness of college students in using mobile online education platforms from the perspective of college students, helping online education enterprises to improve their knowledge, improving the online education level, and strengthening the position of mobile online education in teaching from the consideration of users is necessary.

\section{Theoretical foundation and research hypothesis}

\subsection{Theoretical foundation}

Social learning theory. Ba Ndura, A proposed social learning theory in 1977. Social learning theory emphasized that individual cognition and learning behavior were influenced by environmental factors, and these three factors interact with each other. Self- 
learning was subject to the future expectations of individuals for their learning behaviors, and the development of behaviors was affected by the mutual influence of genetic factors and acquired factors, especially when the observational learning and self-efficacy of students initiated and adjusted the potential role of learning behaviors, and close interaction exists between the learning behavior of students and social environment.

Perceived value theory. Sánchez-Fernández et al. [1] stated that perceived value was "the overall evaluation on the effectiveness of product or service based on the perception of benefits and costs". Therefore, perceived value played an important role when consumers decide whether to buy a product or service. As users, college students can only evaluate the quality of courses by the relevant information from the course introduction to a large extent when they choose the paid courses on mobile online education platforms. In the context of online education, the reputation of the network affects the college students' attitude toward brands and products of mobile online education platforms, and it affects their willingness to use and behaviors. The services provided by online education platforms should be classified as experiential products because it will influence the users' willingness to use. Therefore, the online reputation also affects the college student's perception of the purchase cost of paid courses on mobile online platforms.

\subsection{Research hypothesis}

Exploratory learning can effectively improve the speed and quality of students' knowledge acquisition and skill mastery, as well as fundamentally stimulate the learning enthusiasm of students. Njoo and De Jong [2] investigated the exploratory learning process of using computers for 17 students, which indicated that the exploratory learning could induce learning enthusiasm in students; Rhee [3] showed that the development of the Internet enhanced the exploratory learning environment of students, while exploratory learning became a trend under the Internet model; Spector et al. [4] stated that the development of the digital system and technology in the world has laid the foundation for exploratory learning, exploratory learning can promote learning motivation to students; Ifenthaler et al. [5] reported that exploratory learning can promote the large-scale application technology of educational psychology. Given the preceding discussion, this study proposes the following hypothesis:

- H1-1: Exploratory learning (X1) positively influences the perceived ease of use of mobile online education platforms for college students (M1).

- H1-2: Exploratory learning (X1) positively influences the perceived usefulness of mobile online education platforms for college students (M2).

Mobile online learning is a newer model, when compared with traditional classrooms. For students, the psychological change in learning is mediated by the cognitive process. Therefore, the sense of self-efficacy reflects the students' expectation of the results after studying hard. Schunk [6] believed that self-efficacy was the most important academic motivation, summarizing the evidence of the effect of self-efficacy in predicting the results of motivation; Zimmerman (2000) believed that self-efficacy has 
become the most important factor influencing the learning motivation of students; Bandura and Locke [7] described the functional characteristics of self-efficacy belief and analyzed how self-efficacy belief encourages a person to accomplish the goal; Hsu et al. [8] believed that the model based on social cognition theory (SCT) analyzed the knowledge-sharing behavior in the virtual community; Dinther et al. [9] showed that self-efficacy was an important part of SCT, which was an important variable affecting the learning motivation and learning effect of students. Given the preceding discussion, this study proposes the following hypothesis:

- H2-1: Self-efficacy (X2) positively influences the perceived ease of use of mobile online education platforms for college students (M1).

- H2-2: Self-efficacy (X2) positively influences the perceived usefulness of mobile online education platforms for college students (M2).

Chao et al. [10] explored and discussed the collaborative curriculum development process and the implementation of quality standards in a university in Canada with the introduction of online and distance education into the mainstream of higher education; Grace et al. [11] exhibited that good teaching quality and clear teaching goals had a direct influence on general skill efficacy and student satisfaction. Peterson et al. [12] provided a structured approach to monitor and offer continuous improvement in teaching quality. Durham et al. [13] used the plan-execution-learning-action cycle to accelerate the improvement in teaching quality, which improved the academic writing and feasibility of students. Given the preceding discussion, this study proposes the following hypothesis:

- H3-1: Curriculum quality (X3) positively influences the perceived ease of use of mobile online education platforms for college students (M1).

- H3-2: Curriculum quality (X3) positively influences the perceived usefulness of mobile online education platforms for college students (M2).

The services provided by the online education platforms should be attributed to experience-based products, thus it will have an effect on the users' willingness to use in the case of good online reputation. Nelson et al. [14] believed that differences exist between different products affected by online reputation. He compared experiential products with search products, concluding that the consumers of experiential products paid more attention to the online evaluation. Chevalier and Mayzlin [15] studied the influence of comments made by consumers on book sales on online platforms, which showed that the quantity and quality of comments would increase relative sales of the website. Chen and Xie [16] believed that the comments of online consumers could be regarded as a new element in marketing communication, which could help consumers identify products that fulfill their special conditions and use; Parry et al. [17] developed the technology acceptance model (TAM), including the influence of personal word-ofmouth and virtual word-of-mouth (pWOM and vWOM), which showed that word-ofmouth had a clear perception effect on the selection of product consumption of consumers. Given the preceding discussion, this study proposes the following hypothesis: 
- H4-1: Word-of-mouth (X4) positively influences the perceived ease of use of mobile online education platforms for college students (M1).

- H4-2: Word-of-mouth (X4) positively influences the perceived usefulness of mobile online education platforms for college students (M2).

Davis [18] proposed the theory of the Technology Acceptance Model (TAM). He used the theory of rational behavior to study a model proposed when users accepted the information system, thus proposing that the initial purpose of TAM was to explain the decisive factors that were widely accepted by computers. The TAM proposed two main deciding factors: perceived usefulness, which reflects the extent to which a person thinks that using a specific system will improve his work performance; perceived ease of use, which reflects the extent to which a person thinks that how easy to use a specific system. For college students, mobile online education can effectively enable college students to choose learning resources efficiently, freely adjust learning time, control the learning speed and integrate learning methods, and realize the development of learning potentials of college students, the play of hobby characteristics, cultivation of the innovative and entrepreneurial spirit and spirit shaping of challenging yourself. Therefore, the perceived usefulness and perceived ease of use of college students for mobile online education can determine whether college students should choose such a learning mode. Given the preceding discussion, this study proposes the following hypothesis:

- H5: Perceived ease of use (M1) positively affects the college students' willingness to use mobile online education platforms (Y).

- H6: Perceived usefulness (M2) positively affects the college students' willingness to use mobile online education platforms (Y).

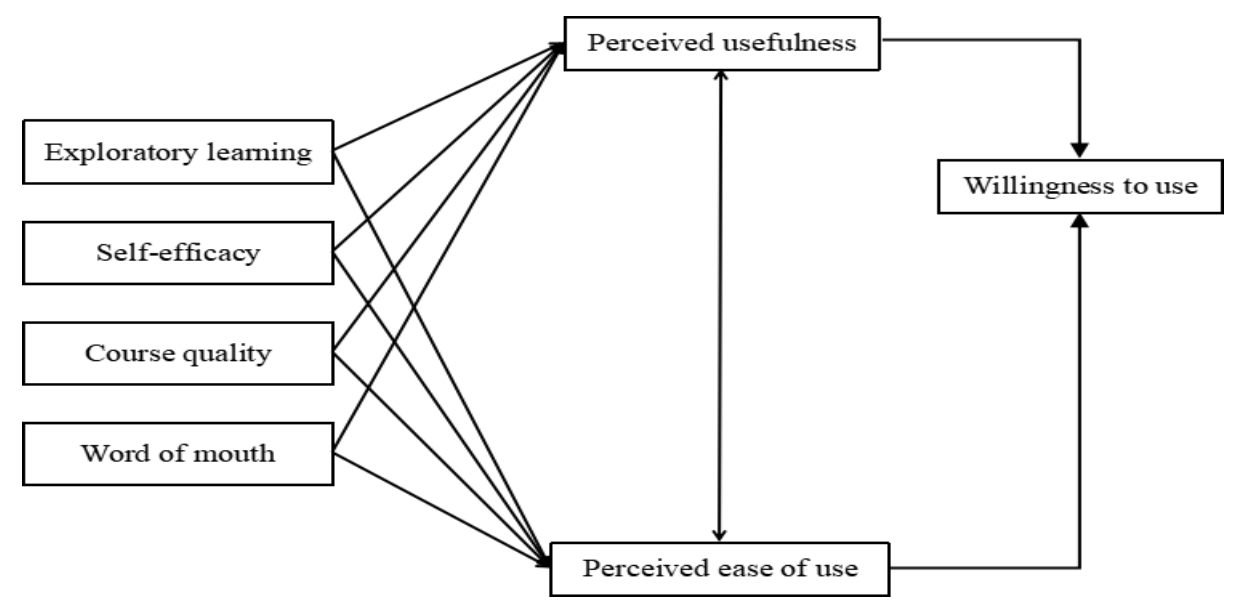

Fig. 1. Analysis Model 


\section{Empirical analysis}

\subsection{Scale design and data collection}

This study designed a questionnaire scale to measure the influencing factors of the college students' willingness to use mobile online education platforms based on previous research on the willingness to purchase learning resources. There were 29 questions on this scale, and the questionnaire comprised three survey parts.

The first part was the basic information survey of college students, which includes four questions; gender, grade, subject, and the choice and use of existing mobile online education platforms.

The second part was the investigation of influencing factors, including exploratory learning (four questions), self-efficacy (four questions) [19-20], curriculum quality (three questions) [21], internet word-of-mouth (three questions) [22], perceived usefulness (four questions) [23] and perceived ease of use (four questions) [24].

The third part was a survey of the college students' willingness to use mobile online platforms, which includes three questions.

The study adopted the questionnaires to collect data and verify the hypotheses proposed. The research objects of this study were college students who had used online education platforms in the ordinary provincial undergraduate study in the author's province. Our research group issued questionnaires through the co-questionnaire star platform. At the end of the five-day questionnaire survey period, a total of 324 questionnaires were collected. After rejecting the non-standard questionnaires, a total of 259 valid questionnaires were collected with an effective recovery rate of $79.94 \%$. In terms of grade distribution, $17.37 \%$ of them are freshmen, $26.64 \%$ of them are sophomores, $28.57 \%$ of them are juniors and $27.41 \%$ of them are seniors; in terms of gender, $47.88 \%$ of them are boys and $52.12 \%$ of them are girls; in terms of subjects, liberal arts accounted for $32.43 \%$, science and engineering accounted for $35.52 \%$ and $32.05 \%$, respectively; in terms of use of the platform, Tencent Classroom, Intelligent Centre Vocational Education Platform (ICVE), Dingding, Zhihuishu, E-learning, Zoom, The Open University of China, MOOC of Universities of China, Tencent MOOC, and other mainstream mobile online learning platforms accounted for $95.75 \%$.

\subsection{Reliability and validity analysis}

First, this study analyzed the reliability and validity of the questionnaire data. In terms of reliability, the Cronbach's $\alpha$ coefficient widely recognized by the academic field was used in most existing studies. It was generally believed that the Cronbach's $\alpha$ coefficient equal to 0.7 was a relatively low, but acceptable scale boundary value. Meanwhile, the larger Cronbach's $\alpha$ was, the better the reliability and stability of the scale would be. According to the value of Cronbach's $\alpha$, it could obtain the reliability indexes of each variable by testing the reliability of data, which is shown in Table 1. The Cronbach's $\alpha$ in the measurement scale of potential influencing factors was more than or equal to 0.7 , which indicated that the measurement reliability of potential variables in the measurement questionnaire of this model was relatively good. At the same 
time, there were 25 effective measurement questions among the seven potential variables in the model. The overall Cronbach's $\alpha$ was 0.926 , which was much higher than the critical value of 0.7 , and had an ideal reliability level. The aforementioned analysis indicated that the reliability $\alpha$ values of each dimension fulfilled the standards of this study, that is, the reliability data of each dimension are good and the questionnaire has good internal consistency.

Table 1. Reliability Test Results

\begin{tabular}{|c|c|c|c|c|}
\hline Name & CITC & $\alpha$ value after deleted the question & \multicolumn{2}{|c|}{ Cronbach $\alpha \square$} \\
\hline $\mathrm{X} 1-1$ & 0.633 & 0.736 & \multirow{4}{*}{0.797} & \multirow{25}{*}{0.926} \\
\hline $\mathrm{X} 1-2$ & 0.59 & 0.756 & & \\
\hline $\mathrm{X} 1-3$ & 0.617 & 0.743 & & \\
\hline $\mathrm{X} 1-4$ & 0.6 & 0.753 & & \\
\hline $\mathrm{X} 2-1$ & 0.38 & 0.722 & \multirow{4}{*}{0.702} & \\
\hline $\mathrm{X} 2-2$ & 0.535 & 0.613 & & \\
\hline $\mathrm{X} 2-3$ & 0.579 & 0.582 & & \\
\hline $\mathrm{X} 2-4$ & 0.49 & 0.639 & & \\
\hline $\mathrm{X} 3-1$ & 0.691 & 0.797 & \multirow{3}{*}{0.842} & \\
\hline $\mathrm{X} 3-2$ & 0.716 & 0.772 & & \\
\hline $\mathrm{X} 3-3$ & 0.716 & 0.772 & & \\
\hline $\mathrm{X} 4-1$ & 0.64 & 0.814 & \multirow{3}{*}{0.831} & \\
\hline $\mathrm{X} 4-2$ & 0.744 & 0.71 & & \\
\hline $\mathrm{X} 4-3$ & 0.689 & 0.768 & & \\
\hline $\mathrm{X} 5-1$ & 0.645 & 0.713 & \multirow{4}{*}{0.786} & \\
\hline $\mathrm{X} 5-2$ & 0.481 & 0.789 & & \\
\hline $\mathrm{X} 5-3$ & 0.693 & 0.679 & & \\
\hline X5-4 & 0.573 & 0.745 & & \\
\hline X6-1 & 0.728 & 0.91 & \multirow{4}{*}{0.912} & \\
\hline X6-2 & 0.838 & 0.872 & & \\
\hline X6-3 & 0.834 & 0.873 & & \\
\hline X6-4 & 0.797 & 0.886 & & \\
\hline Y1-1 & 0.578 & 0.76 & \multirow{3}{*}{0.785} & \\
\hline Y1-2 & 0.688 & 0.635 & & \\
\hline Y1-3 & 0.617 & 0.721 & & \\
\hline
\end{tabular}

The validity refers to the degree to which the scale can truly measure the ability or function to be measured, and the scale was valid only when it achieved the measurement purpose. The degree of scale test or questionnaire validity was called the validity test of questionnaire data. Results were shown in Table 2, wherein the KMO value was $0.899>0.8$, and the corresponding $p$-value is 0.000 , which indicated that the questionnaire had passed the validity test. 
Table 2. Reliability Test Results

\begin{tabular}{|l|c|c|}
\hline \multicolumn{2}{|c|}{ KMO value } & $\mathbf{0 . 8 9 9}$ \\
\hline \multirow{3}{*}{ Bartlett's test of sphericity } & Approximate chi-square & 3563.002 \\
\cline { 2 - 3 } & $d f$ & 300 \\
\cline { 2 - 3 } & $p$ & 0.000 \\
\hline
\end{tabular}

\subsection{Empirical test}

In this study, AMOS22.0 was used to calculate the relevant parameters in the model. It calculated the fitness of the model, while the results were obtained after fitting and modifying the model, which is shown in Table 3. It can be seen from the table that seven of the eight commonly-used test indicators were within the fitting standard, which indicated that the research model had a good fitness.

Table 3. Fitting Indicators of the Model

\begin{tabular}{|l|c|c|c|c|c|c|c|c|}
\hline Common indicator & GFI & RMSEA & RMR & CFI & NFI & NNFI & IFI & SRMR \\
\hline Judgment standard & $>0.9$ & $<0.10$ & $<0.05$ & $>0.9$ & $>0.9$ & $>0.9$ & $>0.9$ & $<0.1$ \\
\hline Value & 0.918 & 0.08 & 0.035 & 0.939 & 0.934 & 0.744 & 0.94 & 0.068 \\
\hline
\end{tabular}

And then carry on path test for the structural model, and then verify the hypothesis. As shown in Table 4, by estimating the path coefficient value by the maximum likelihood method, it was found that six of the 10 hypotheses were valid at the $1 \%$ significance level; one hypothesis was valid at the $10 \%$ significance level, while three hypotheses were invalid. Table 4 shows that:

Table 4. Summary of regression coefficients

\begin{tabular}{|l|c|c|c|c|c|c|c|}
\hline $\mathbf{X}$ & $\rightarrow$ & $\mathbf{Y}$ & $\mathbf{S E}$ & $\mathbf{z}(\mathbf{C R})$ & $\boldsymbol{p}$ & $\begin{array}{c}\text { Standardized path } \\
\text { coefficient }\end{array}$ & $\begin{array}{c}\text { Hypothesis test } \\
\text { result (Y/N) }\end{array}$ \\
\hline $\mathrm{X} 1$ & $\rightarrow$ & $\mathrm{M} 1$ & 0.076 & 4.141 & 0.000 & 0.293 & $\mathrm{H} 1-1 \mathrm{Y}$ \\
\hline $\mathrm{X} 1$ & $\rightarrow$ & $\mathrm{M} 2$ & 0.069 & 4.997 & 0.000 & 0.297 & $\mathrm{H} 1-2 \mathrm{Y}$ \\
\hline $\mathrm{X} 2$ & $\rightarrow$ & $\mathrm{M} 1$ & 0.069 & -0.964 & 0.335 & -0.064 & $\mathrm{H} 2-1 \mathrm{~N}$ \\
\hline $\mathrm{X} 2$ & $\rightarrow$ & $\mathrm{M} 2$ & 0.062 & 2.792 & 0.005 & 0.156 & $\mathrm{H} 2-2 \mathrm{Y}$ \\
\hline $\mathrm{X} 3$ & $\rightarrow$ & $\mathrm{M} 1$ & 0.076 & 0.774 & 0.439 & 0.066 & $\mathrm{H} 3-1 \mathrm{~N}$ \\
\hline $\mathrm{X} 3$ & $\rightarrow$ & $\mathrm{M} 2$ & 0.069 & 1.897 & 0.058 & 0.136 & $\mathrm{H} 3-2 \mathrm{Y}$ \\
\hline $\mathrm{X} 4$ & $\rightarrow$ & $\mathrm{M} 1$ & 0.066 & 2.836 & 0.005 & 0.217 & $\mathrm{H} 4-1 \mathrm{Y}$ \\
\hline $\mathrm{X} 4$ & $\rightarrow$ & $\mathrm{M} 2$ & 0.06 & 3.691 & 0.000 & 0.237 & $\mathrm{H} 4-2 \mathrm{Y}$ \\
\hline $\mathrm{M} 1$ & $\rightarrow$ & $\mathrm{Y}$ & 0.053 & 1.493 & 0.136 & 0.085 & $\mathrm{H} 5 \mathrm{~N}$ \\
\hline $\mathrm{M} 2$ & $\rightarrow$ & $\mathrm{Y}$ & 0.049 & 7.754 & 0.000 & 0.443 & $\mathrm{H} 6 \mathrm{Y}$ \\
\hline
\end{tabular}

This study proved that Hypothesis H5 was invalid. This is probably because of the large variety of mobile online platforms. In real teaching, various teachers adopt different mobile teaching platforms, which may lead to frequent switching between different 
mobile online learning platforms. As a result, the self-experience and academic performance of mobile online learning platforms failed to achieve the expected results, thus incurring negative emotions, which largely reduced the willingness of college students to use mobile learning platforms, along with the login rate, click rate, and utilization rate, which meant that college students could no longer use mobile online learning platforms and would even uninstall them.

This study proved that Hypothesis H6 was valid. The perceived usefulness for college students could positively affect their willingness to use online education platforms, and the $\mathrm{CR}$ value was 7.754. In the process of using mobile online education platforms, the usefulness of the platform was an important factor to be taken into account in the design process. The usefulness of educational products determined other ways of learning for college students, aside from daily classroom teaching. The usefulness was the basis for maintaining its use by college students. The enterprises should conduct a large number of market research and develop relevant products suitable for college students to study online. Mobile online learning platforms could realize college students' demands for mobile and other ubiquitous learning methods and made their learning time and spaces extend infinitely. Especially when compared with the traditional classroom teaching model, it had the function of teaching data collection, analysis, and feedback in the process of mobile online learning, so that the students could timely capture learning results at the first time, and then made students from learning objects into the main body of mobile online education mode so that college students could learn with strong subjective desire and more acceptable way, and thus greatly improved their perceived usefulness.

This allows college students to have the first time capture of the learning effect in time.

This study proved that Hypothesis H1-1 and H1-2 were valid. Exploratory learning positively affected the college students' perceived ease of use and perceived usefulness of mobile online education platforms, especially under the current situation, which stems from the pandemic. Mobile online platform education had become an alternative to traditional teaching methods. The students with strong subjective initiative could effectively participate in mobile online learning, adopt exploratory learning, and acquire a stronger sense of self-efficacy and familiarity with a large number of learning resources and accept mobile online education under the mobile Internet mode. Positive exploratory learning was inseparable from the willingness to use the platform. During the learning process, the academic performance and intellectual development of learners further drove the value perception of the platform, thus promoting the use of mobile online platforms.

This study proved that Hypothesis H2-1 was invalid and Hypothesis $\mathrm{H} 2-2$ was valid. The self-efficacy positively affected the perceived usefulness of college students toward mobile online education platforms, but it did not affect the perceived ease of use. As the groups with rich knowledge reserve in the education groups, college students had a clear understanding of the usefulness of mobile online education platforms to promoting their self-development. However, under the mode of mobile networks, college students expressed themselves socially and emotionally through communication media. Because there are numerous mobile online learning platforms in China, college 
students spend plenty of time exploring, which leads to reduced perceived ease of use. Self-efficacy is the main factor affecting the learning behavior and willingness of college students. However, rich mobile online learning resources improved the ease of learning. By contrast, the complicated use of technology also affected the willingness of students to exert an effort. The difficulty of using digital resources and learning platforms will reduce the mobile self-efficacy of learners. Therefore, paying more attention to the simplicity of the platform and the richness of resources to enhance the college students' willingness to learn online is necessary.

This study proved that Hypothesis H3-1 was invalid and Hypothesis H3-2 was valid. The curriculum quality positively affected the perceived usefulness of college students toward mobile online education platforms, but it did not affect the perceived ease of use. The main reason was that most universities had purchased various high-quality mobile online learning resources, which made the college students' learning results on mobile online platforms more remarkable, thus making them effectively understand the pertinence and effectiveness of mobile online education platforms. However, the universities also provided free mobile online platforms for college students while purchasing high-quality mobile online education platform resources. These free platforms had uneven learning resources, in which that college student can spend a lot of time looking for resources on these platforms, reducing the learning experience of college students.

This study proved that Hypothesis H4-1 and Hypothesis H4-2 were valid. The Internet word-of-mouth positively affected the perceived ease of use and the perceived usefulness of college students toward mobile online education platforms. Good Internet word-of-mouth evaluation could strengthen the college student's perception of mobile online education platforms and improve their perceived value, which could also directly and positively affect the college students' perceived ease of use and perceived usefulness toward online education platforms. During mobile online classes, in addition to the platforms stipulated by the colleges and universities, college students had more recommendations from classmates and teachers, as well as network social media. Therefore, online education enterprises should accurately grasp the consumption psychology of college students, build the brand image through word of mouth, attract college students through a variety of ways, and enhance user viscosity and word-of-mouth, thus gathering a large number of students on the high-quality mobile online education platform, and producing a "Matthew effect" upon mobile online education platforms.

\section{Conclusion}

Under the strategic promotion of China's "Internet + Education" policy and the background of COVID-19, the mobile online education industry is accelerating. The products and services provided by mobile online education platforms have become personalized and diversified. The network-learning ability of college students is becoming stronger and online education is likely to become an important way for college students to acquire knowledge. Mobile online education platforms are effective supplements to traditional education modes in the era of "Internet+", which provided a new direction for the development of new education technology. Based on the theory of perceived 
value, the hypotheses on factors affecting the college students' willingness to use mobile online education platforms were proposed, and the hypothesis with a questionnaire survey method and structural equation model was verified.

The conclusions are as follows: (1) the questionnaire designed in this study has good reliability and validity. (2) Exploratory learning and online word-of-mouth positively influence the college students' perceived ease of use and perceive usefulness toward mobile online education platforms. (3) The perceived usefulness of college students has a significant and direct effect on their willingness to use online education platforms.

It is suggested that further research can be conducted on the individual characteristics of learners on mobile education platforms, the use of integration based on educational information technology, the differential effect of the development frontier of the emerging technology industry on education, and the learning motivation and incentive mechanism of college students at various educational levels.

\section{$5 \quad$ Acknowledgment}

This study was supported by the Humanities and Social Science Research Project of Hubei Provincial Department of Education (NO.19Y104).

\section{References}

[1] Sánchez-Fernández, R., Iniesta-Bonillo, M. Á. (2007). The concept of perceived value: a systematic review of the research. Marketing Theory, 7(4): 427-451. https://doi.org/10. $1177 / 1470593107083165$

[2] Njoo, M., \& De Jong, T. (1993). Exploratory learning with a computer simulation for control theory: learning processes and instructional support. Journal of Research in Science Teaching, 30(8): 821-844. https://doi.org/10.1002/tea.3660300803

[3] Rhee, M. (2010). Network updating and exploratory learning environment. Journal of Management Studies, 41(6): 933-949. https://doi.org/10.1111/j.1467-6486.2004.00461.x

[4] Spector, J. M., Ifenthaler, D., Sampson, D. G. (2016). Digital systems supporting cognition and exploratory learning in twenty-first century: guest editorial. Journal of Computing in Higher Education, 28: 301-306. https://doi.org/10.1007/s12528-016-9114-0

[5] Ifenthaler, D., Sampson, D. G., Spector, J. M. (2017). Linking analytics data and digital systems for supporting cognition and exploratory learning in 21st century. Computers in Human Behavior, 78: 348-350.https://doi.org/10.1016/i.chb.2017.10.016

[6] Schunk, D. H. (1991). Self-efficacy and academic motivation. Educational Psychologist, 26(3-4): 207-231. https://doi.org/10.1207/s15326985ep2603\&4 2

[7] Bandura, A., Locke, E. A. (2003). Negative self-efficacy and goal effects revisited. Journal of Applied Psychology, 88(1), 87-99. https://doi.org/10.1037/0021-9010.88.1.87

[8] Hsu, M. H., Ju, T. L., Yen, C. H., Chang, C. M. (2007). Knowledge sharing behavior in virtual communities: the relationship between trust, self-efficacy, and outcome expectations. International Journal of Human-Computer Studies, 65(2): 153-169. https://doi.org/10. 1016/j.ijhcs.2006.09.003

[9] Dinther, M. V., Dochy, F., Segers, M. (2011). Factors affecting students' self-efficacy in higher education. Educational Research Review, 6 (2): 95-108. https://doi.org/ $\underline{10.1016 / \text { j.edurev.2010.10.003 }}$ 
[10] Chao, I. T., Saj, T., Hamilton, D. (2010). Using collaborative course development to achieve online course quality standards. International Review of Research in Open and Distributed Learning, 11(3): 106-126. https://doi.org/10.19173/irrodl.v11i3.912

[11] Grace, D., Weaven, S., Bodey, K., Ross, M., Weaven, K. (2012). Putting student evaluations into perspective: the course experience quality and satisfaction model (CEQS). Studies in Educational Evaluation, 38(2): 35-43. https://doi.org/10.1016/j.stueduc.2012.05.001

[12] Peterson, S. L., Wittstrom, K. M., Smith, M. J. (2011). A course assessment process for curricular quality improvement. American Journal of Pharmaceutical Education, 75 (8): 157. https://doi.org/10.5688/ajpe758157

[13] Durham, M. L., Yingling, C., Hershberger, P. E. (2019). Accelerating improvement of a doctor of nursing practice project proposal course using quality improvement methods. Journal of Nursing Education, 58(5): 306-311. https://doi.org/10.3928/01484834-20190422-11

[14] Nelson, R. R., Todd, P. A., Wixom, B. H. (2005). Antecedents of information and system quality: an empirical examination within the context of data warehousing. Journal of Management Information Systems, 21(4): 199-235. https://doi.org/10.1080/07421222.2005 .11045823

[15] Chevalier, J. A., Mayzlin, D. (2006). The effect of word of mouth on sales: Online book reviews. Journal of Marketing Research, 43(3): 345-354. https://doi.org/10.1509/jmkr. 43.3 .345

[16] Chen, Y., Xie, J. (2008). Online consumer review: Word-of-mouth as a new element of marketing communication mix. Management Science, 54 (3), 477-491. https://doi.org/10. $1287 /$ mnsc. 1070.0810

[17] Parry, M. E., Kawakami, T., Kishiya, K. (2012). The effect of personal and virtual word of - mouth on technology acceptance. Journal of Product Innovation Management, 29(6): 952-966. https://doi.org/10.1111/j.1540-5885.2012.00972.x

[18] Davis, F. D. (1989). Technology Acceptance Model: TAM. Al-Suqri, MN, Al-Aufi, AS: Information Seeking Behavior and Technology Adoption, S: 205-219.

[19] Bandura, A. (1977). Self-efficacy: toward a unifying theory of behavioral change. Psychological Review, 84(2): 191-215. https://doi.org/10.1037/0033-295x.84.2.191

[20] Zimmerman, B. J. (2000). Self-efficacy: an essential motive to learn. Contemporary Educational Psychology, 25(1): 82-91. https://doi.org/10.1006/ceps.1999.1016

[21] Hill, H. C., Lovison, V., Kelley-Kemple, T. (2019). Mathematics teacher and curriculum quality, 2005 and 2016. AERA Open, 5(4): 2332858419880521. https://doi.org/10.1177/ 2332858419880521

[22] Gu, D., Yang, X., Li, X., Jain, H. K., Liang, C. (2018). Understanding the role of mobile internet-based health services on patient satisfaction and word-of-mouth. International Journal of Environmental Research and Public Health, 15(9): 1972. https://doi.org/10.3390/ ijerph15091972

[23] Moslehpour, M., Pham, V. K., Wong, W. K., Bilgiçli, İ. (2018). E-purchase intention of Taiwanese consumers: Sustainable mediation of perceived usefulness and perceived ease of use. Sustainability, 10(1): 234. https://doi.org/10.3390/su10010234

[24] Hansen, J. M., Saridakis, G., Benson, V. (2018). Risk, trust, and the interaction of perceived ease of use and behavioral control in predicting consumers' use of social media for transactions. Computers in Human Behavior, 80: 197-206. https://doi.org/10.1016/j.chb. $\underline{2017.11 .010}$ 


\section{$7 \quad$ Authors}

Qian Feng, Master's degree, Associate professor, is a lecturer at School of International Education, Hubei Engineering University. His research interests focus on foreign linguistics and applied linguistics, pragmatics, cross-cultural communication (Email: nwy_hb@163.com).

Beikun Feng, Master's degree candidate, in the School of Vocational and Technical Education, Hubei University of Technology, His research interests focus on vocational and technical education.

Article submitted 2021-09-07. Resubmitted 2021-10-08. Final acceptance 2021-10-08. Final version published as submitted by the authors. 